\title{
Mechanisms of reduced peak oxygen consumption in subjects with uncomplicated type 2 diabetes
}

\author{
Lorenzo Nesti ${ }^{1,2^{*}+}$ (D), Nicola Riccardo Pugliese ${ }^{2 \dagger}{ }^{\text {, Paolo Sciuto }}{ }^{1}$, Nicolò De Biase ${ }^{2}$, Matteo Mazzola ${ }^{2}$, \\ lacopo Fabiani ${ }^{3}$, Domenico Trico ${ }^{1,4}$, Stefano Masi ${ }^{2}$ and Andrea Natali ${ }^{1,2}$
}

\begin{abstract}
Background: Type 2 diabetes mellitus (T2D) increases the risk of incident heart failure (HF), whose earliest fingerprint is effort intolerance (i.e. impaired peak oxygen consumption, or $\mathrm{VO}_{2 \text { peak }}$ ). In the uncomplicated T2D population, however, the prevalence of effort intolerance and the underpinning mechanistic bases are uncertain. Leveraging the multiparametric characterization allowed by imaging-cardiopulmonary exercise testing (iCPET), the aim of this study is to quantify effort intolerance in T2D and to dissect the associated cardiopulmonary alterations.
\end{abstract}

Methods: Eighty-eight adults with well-controlled and uncomplicated T2D and no criteria for HF underwent a maximal iCPET with speckle tracking echocardiography, vascular and endothelial function assessment, as well as a comprehensive biohumoral characterization. Effort intolerance was defined by a $\mathrm{VO}_{2 \text { peak }}$ below $80 \%$ of maximal predicted oxygen uptake.

Results: Forty-eight patients (55\%) had effort intolerance reaching a lower $\mathrm{VO}_{2 \text { peak }}$ than $\mathrm{T} 2 \mathrm{D}$ controls $(16.5 \pm 3.2 \mathrm{~mL} /$ $\mathrm{min} / \mathrm{kg}$, vs $21.7 \pm 5.4 \mathrm{~mL} / \mathrm{min} / \mathrm{kg}, \mathrm{p}<0.0001)$. Despite a comparable cardiac output, patients with effort intolerance showed reduced peak peripheral oxygen extraction ( $11.3 \pm 3.1 \mathrm{vs} 12.7 \pm 3.3 \mathrm{~mL} / \mathrm{dL}, \mathrm{p}=0.002$ ), lower $\mathrm{VO}_{2} /$ work slope ( $9.9 \pm 1.2$ vs $11.2 \pm 1.4, p<0.0001$ ), impaired left ventricle systolic reserve (peak $S^{\prime} 13.5 \pm 2.8$ vs $15.2 \pm 3.0, p=0.009$ ) and global longitudinal strain (peak-rest $\triangle \mathrm{GLS} 1.7 \pm 1.5 \mathrm{vs} 2.5 \pm 1.8, \mathrm{p}=0.03$ ) than subjects with $\mathrm{VO}_{2 \text { peak }}$ above $80 \%$. Diastolic function, vascular resistance, endothelial function, biohumoral exams, right heart and pulmonary function indices did not differ between the two groups.

Conclusions: Effort intolerance and reduced $\mathrm{VO}_{2 \text { peak }}$ is a severe and highly prevalent condition in uncomplicated, otherwise asymptomatic T2D. It results from a major defect in skeletal muscle oxygen extraction coupled with a subtle myocardial systolic dysfunction.

Keywords: Type 2 diabetes, Effort intolerance, Heart failure with preserved ejection fraction, Exercise physiology, Cardiopulmonary exercise test, Diabetic cardiomyopathy

${ }^{*}$ Correspondence: lorenzo.nesti@phd.unipi.it

'Lorenzo Nesti and NicolaRiccardo Pugliese contributed equally to this work

${ }^{1}$ Metabolism, Nutrition, and Atherosclerosis Laboratory, Department of Clinical and Experimental Medicine, University of Pisa, Via Savi 10, 56126 Pisa, Italy

Full list of author information is available at the end of the article

\section{Background}

Defined as the inability to perform physical exercise at the maximal intensity expected (according to age, gender, body mass index (BMI), and habitual levels of physical activity [1]), effort intolerance can be quantified and objectively measured by peak oxygen consumption $\left(\mathrm{VO}_{2 \text { peak }}\right)$ during a graded maximal exercise test. Effort

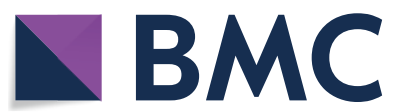

(c) The Author(s) 2021. This article is licensed under a Creative Commons Attribution 4.0 International License, which permits use, sharing, adaptation, distribution and reproduction in any medium or format, as long as you give appropriate credit to the original author(s) and the source, provide a link to the Creative Commons licence, and indicate if changes were made. The images or other third party material in this article are included in the article's Creative Commons licence, unless indicated otherwise in a credit line to the material. If material is not included in the article's Creative Commons licence and your intended use is not permitted by statutory regulation or exceeds the permitted use, you will need to obtain permission directly from the copyright holder. To view a copy of this licence, visit http://creativeco mmons.org/licenses/by/4.0/. The Creative Commons Public Domain Dedication waiver (http://creativecommons.org/publicdomain/ zero/1.0/) applies to the data made available in this article, unless otherwise stated in a credit line to the data. 
intolerance is the hallmark of heart failure (HF), is part of the definition of the HF syndrome and is intimately linked to its pathophysiology [2]. Given that type 2 diabetes mellitus (T2D) portends an increased risk of developing $\mathrm{HF}$-especially HF with preserved ejection fraction (HFpEF) - that is neither entirely explained by traditional cardiovascular risk factors nor by coronary heart disease, an early, primary cardiopulmonary impairment has been postulated, but never clearly demonstrated [3]. Effort intolerance was previously reported in otherwise asymptomatic subjects with T2D, with slower oxygen uptake kinetics and reduced peak values in comparison to normal subjects during cardiopulmonary exercise test (CPET) [4]. Notably, reduced $\mathrm{VO}_{2 \text { peak }}$ is a reliable predictor of cardiovascular disease, all-cause mortality [5], development of HF [6], and reduced quality of life in T2D [7]. According to current guidelines, the early appearance of effort intolerance is a marker of subclinical HF (American Heart Association stage B), whose early recognition justifies a more aggressive diagnostic-therapeutic workup. To date, however, the prevalence of effort intolerance in T2D is unclear, and so are the underlying mechanisms [4], leaving the prevention strategies for HF in T2D uncertain.

With the present study, we aim at quantifying the prevalence of effort intolerance in an outpatient, uncomplicated, and otherwise asymptomatic T2D population. Participants underwent exercise echocardiography during a maximal imaging-CPET (iCPET), which allows the dissection of the pathophysiological mechanisms underlying a reduced $\mathrm{VO}_{2 \text { peak }}$ by simultaneous measurement of the major determinants of exercise physiology.

\section{Patients and methods}

\section{Study population}

We prospectively enrolled 114 patients from the Diabetes Outpatient Clinic at the Santa Chiara University Hospital of Pisa. Inclusion criteria were: men or women of 40 to 80 years of age with a clinical diagnosis of T2D according to the ADA criteria [8]; $\mathrm{HbA}_{1 \mathrm{c}}$ values between 53 and $69 \mathrm{mmol} / \mathrm{mol}$ (7.0 to $8.0 \%$ ); on stable hypoglycemic and cardioactive therapy for at least 3 months; baseline echocardiographically-assessed left ventricle ejection fraction (LVEF) above 50\%; without a dignosis of $\mathrm{HF}$ according to guidelines [9]. Exclusion criteria were: symptoms or diagnosis of HF, serum BNP above $100 \mathrm{pg} /$ $\mathrm{mL}$, any established cardiovascular disease, presence of retinopathy (at ophtalmology), peripheral artery disease, peripheral or cardiac neuropathy, respiratory insufficiency or diagnosis of chronic obstructive pulmonary disease (more than moderate airflow obstruction (forced expiratory volume in $1 \mathrm{~s}$ [FEV1] to forced vital capacity [FVC] ratio $<0.70$ and FEV1 $<50 \%$ of predicted FEV1) and/or restrictive pattern ( $<80 \%$ of predicted FVC)); pulmonary hypertension; any acute or chronic inflammatory disease; severe obesity defined as body mass index (BMI) $>40 \mathrm{~kg} / \mathrm{m}^{2}$; uncontrolled blood pressure defined as $\mathrm{BP}>160 / 100 \mathrm{mmHg}$; impaired kidney function defined as estimated glomerular filtration rate $(\mathrm{eGFR})<60 \mathrm{~mL} /$ $\min / 1.73 \mathrm{~m}^{2}$; uncontrolled arrhythmias (including atrial fibrillation); any more than mild valvular disesase; inability to cycle due orthopedic limitations; poor echocardiographical acoustic windows; ongoing pregnancy or breastfeeding.

The definitive inclusion/exclusion criteria were reassessed both after the baseline evaluation and after the iCPET. The Local Ethic Committee approved the study protocol. All patients gave written informed consent before enrolment.

\section{Patient characterization}

\section{i. Clinical characterization}

A full clinical history was obtained. Baseline demographic data, anthropometric variables (height, weight and body mass index, BMI), functional status, cardiovascular risk factors (e.g. family history of cardiovascular disease, alcohol and smoking habits), comorbidities (e.g. arterial hypertension, dyslipidemia), and medication were also recorded. A thorough physical exam was also performed, including resting vital parameters. All patients underwent a resting cardiac echocardiography (see later for "baseline, speckle tracking, and exercise echocardiography") and electrocardiogram.

ii. Biohumoral characterization

Blood cell count, $\mathrm{HbA}_{1 \mathrm{c}}$, blood lipids, creatinine, electrolytes, uric acid, hepatic function, urinalysis, erythrocytes sedimentation rate, high-sensitivity C-reactive protein, BNP, urine albumin-to-creatinine ratio (ACR) were recorded at baseline. eGFR was calculated through the CKD-EPI formula.

iii. Vascular assessment

Patients underwent peripheral vascular disease assessment through the cardio-ankle vascular index (CAVI) and ankle-brachial index (ABI) with the Vascular Screening System VaSera VS-1500 N ${ }^{\circledR}$ (Fukuda Denshi, Japan) to rule out peripheral vascular disease. Endothelial function was assessed by downstream hyperemic response to ischemia using an EndoPAT device (EndoPAT 2000, Itamar Medical Ltd., Caesarea, Israel), according to standard procedures [10]. The reactive hyperemia index (RHI) was calculated as the ratio between post- and 
pre-occlusion amplitudes of the pulse, normalized to the contralateral arm.

iv. Screening of neuropathy

All patients underwent a thorough neurological clinical examination by a trained physician, as well as screening of neurological complications by the Semmens-Weinstein monofilament test and Neurotester ${ }^{\circledR}$ to exclude the presence of neurological complications. The monofilament test was performed according to standard procedures [11] for the screening of peripheral sensory-motor neuropathy. The screening of the cardiac autonomic neuropathy (CAN) was performed with the Neurotester $^{\circledR}$ (Meteda srl, San Benedetto del Tronto, Italy): variations in RR intervals in response to the Valsalva manoeuvre, lying-to-standing, and deep breathing, according to standard procedures [12]. The three tests were repeated three times each for each patient. Two or more abnormal tests, based on age-related normal values, identified the presence of CAN.

\section{Cardiopulmonary exercise test (CPET) protocol}

A symptom-limited graded ramp bicycle exercise test was performed in the semi-supine position on a tilting, dedicated, microprocessor-controlled stress echocardiography cycle ergometer (Ergoline ergoselect $2000 \mathrm{GmbH}$, Germany). A 12-lead electrocardiogram and non-invasive arterial saturation and blood pressure (BP) were monitored continuously. Heart rate (HR) and brachial BP were measured at rest and every minute during exercise using a validated automatic device (Omron M6 Comfort, Kyoto, Japan). The expected $\mathrm{VO}_{2 \text { peak }}$, estimated on the bases of patient age, height, weight and clinical history [1], was used to adjust the ramp increments (Watt) to reach the patient's estimated $\mathrm{VO}_{2 \text { peak }}$ in 8 to $12 \mathrm{~min}$. The protocol included two minutes of unloaded pedalling and four minutes of recovery after peak effort. Then, we excluded from the analysis patients who did not reach a RER $>1.0$ during the exercise test. Breath-by-breath minute ventilation, carbon dioxide production $\left(\mathrm{VCO}_{2}\right)$, and $\mathrm{VO}_{2}$ were measured using a dedicated cardiopulmonary diagnostic device (Blue Cherry, Geratherm Respiratory $\mathrm{GmbH}$, Germany). We defined $\mathrm{VO}_{2 \text { peak }}$ as the highest median value of the two 30-s intervals of the last minute of exercise, as previously extensively validated [13-17]. An automatic procedure determined anaerobic threshold (AT) based on the V-slope, ventilatory equivalents and end-tidal partial pressure methods; AT was verified visually and, if necessary, recalculated [1].

The chronotropic response was calculated as the change in HR from rest to peak exercise, divided by the difference between the age-predicted maximal HR and the resting HR (i.e. HR reserve). Chronotropic incompetence was defined as the failure to achieve $\geq 80 \%$ of the HR reserve during exercise [18]. In patients on $\beta$-blockers or calcium-channel blockers, chronotropic incompetence was defined as the failure to achieve $62 \%$ of HR reserve [18].

\section{Baseline, speckle tracking, and exercise stress echocardiography protocol}

All patients underwent a comprehensive transthoracic echocardiography examination at rest (GE healthcare vivid e95, Milwaukee, WI, USA) according to the International Recommendations [19]. Data collected at each stage, that is at baseline, after $4 \mathrm{~min}$, at the AT, and at peak effort, included: left ventricle (LV) and atrial (LA) volumes, stroke volume (SV), peak E-wave and A-wave velocities, tissue Doppler imaging (TDI)-derived S' and e' at the septal and lateral mitral annulus, tricuspid regurgitation velocity and systolic pulmonary artery pressure (sPAP), tricuspid annular plane systolic excursion (TAPSE); LV volumes and LVEF were calculated from the apical two- and four-chamber views using the modified Simpson's rule. SV was calculated by multiplying the LV outflow tract area at rest by the LV outflow tract velocity-time integral measured by pulsed-wave Doppler during each activity level, as previously validated [20-23]. Cardiac output was calculated as the multiplication of $\mathrm{SV}$ and HR. The $\Delta(\mathrm{a}-\mathrm{v}) \mathrm{O}_{2}$ was estimated indirectly with a validated and previously used approach by different groups using both our combined iCPET approach [24] and in a different setting with CPET and right heart catheterization [25]. Images were acquired concurrently with breath-by-breath gas exchange measurements at both baseline and peak of exercise. All measurements were reported as the average of three beats.

We measured global longitudinal strain (GLS) from the apical long-axis view and two- and four-chamber views, ensuring a frame rate $>50 \mathrm{~Hz}$ (GE healthcare EchoPAC BT 12). We reported the average values from the three apical views at rest and low-load effort, within the first 4 min of exercise. We excluded poorly tracked segments and patients were not analysed if more than one segment per view was deemed unacceptable. STE-derived measurements were reported as the average of three beats.

\section{Statistical analysis}

Analyses were performed using JMP Pro software version 13.2.1 (SAS Institute, Cary, NC). Values are presented as mean $\pm S D$, or as median and interquartile range (IQR), for variables with normal and non-normal distribution, respectively. Variables with a non-normal distribution at Kolmogorov-Smirnov test were logarithmically transformed for parametric analysis. Comparisons between 
groups were made by the Student $\mathrm{t}$-test for unpaired data for continuous variables and by the chi-square test for categorical variables. All tests were conducted at a twosided $\alpha$ level of 0.05 .

In order to exclude drug-related chronotropic incompetence, we performed a sensitivity analysis after having excluded the subgroup taking beta-blockers, which confirmed the results of the analysis on the whole population (see Additional file 1: Table S4). Factors with ascertained or potential influence on $\Delta(\mathrm{a}-\mathrm{v}) \mathrm{O}_{2}$ were selected for univariate linear regression analysis (age, sex, BMI, duration of diabetes, $\mathrm{HbA}_{1 \mathrm{c}}$, smoke, presence of hypertension, treatment with metformin, creatinine, ACR, PCR, hemoglobin, RHI, CAVI, ABI, MBP at peak, SVR at peak, CO at peak, LVEF at rest and at peak, $\triangle \mathrm{LVEF}, \mathrm{GLS}$ at rest and at $4 \mathrm{~min}, \triangle \mathrm{GLS}, \mathrm{S}^{\prime}$ at rest and at peak, $\triangle \mathrm{S}$, E/e' peak, VE/ $\mathrm{VCO}_{2}$ slope). In order to reduce overfitting, clinical, biohumoral, echocardiography, and CPET variables showing a $\mathrm{p}$ value $<0.100$ at univariate analysis, were pooled into the multiple for multivariate analysis. Factors with ascertained or potential influence on $\mathrm{VO}_{2 \text { peak }}$ age, sex, BMI, duration of diabetes, $\mathrm{HbA}_{1 \mathrm{c}}$, creatinine, eGFR, ACR, PCR,

hemoglobin, RHI, CAVI, HR at peak, chronotropic incompetence, MBP at peak, SVR at peak, CO at peak, LVEF at rest and at peak, $\triangle \mathrm{LVEF}, \mathrm{GLS}$ at rest and at 4 min, $\triangle G L S, S$ at rest and at peak, $\Delta S$, E/e' peak, VE/ $\mathrm{VCO}_{2}$ slope) were selected for univariate linear regressions. Shapiro-Wilk test was used for normal data, and Breusch-Pagan/Cook-Weisberg test was used for heteroskedasticity in the multiple regression models. A p value $<0.05$ was considered statistically significant.

\section{Results}

\section{Baseline characteristics of the study population}

According to the inclusion and exclusion criteria, 114 consecutive patients were recruited for the study from December 2017 to July 2020; after baseline evaluation, 26 were subsequently excluded because of definitive exclusion criteria ( 10 for suboptimal ultrasound images during the exercise, 10 for incapacity of performing a maximal CPET due to discomfort, 4 for ECG signs suggestive of ischemia, 2 for evidence of autonomic neuropathy); the analysis was performed on 88 T2D subjects who met the definitive inclusion/exclusion criteria. We defined exercise intolerance as the incapacity of reaching a $\mathrm{VO}_{2 \text { peak }}>80 \%$ of predicted $\mathrm{VO}_{2 \max }$, which occurred in 48 subjects (55\%). Baseline characteristics of the whole population and according to the presence or absence of effort intolerance are reported in Table 1.

The two groups had similar numerosity, sex prevalence, BMI, glycemic control, blood pressure values, prevalence of comorbidities, treatment for diabetes and cardio-active therapy. The group with preserved exercise capacity was slightly older, with a congruent marginally lower eGFR despite comparable values of serum creatinine. The group reaching a lower $\mathrm{VO}_{2 \text { peak }}$ showed lower HDL-cholesterol values, despite comparable values of other blood lipids and prevalence of lipid lowering treatment, diuretics and beta blockers. At baseline echocardiography (Table 2), all patients showed normal RV and LV dimensions, mass, diastolic, and 2D systolic function (LVEF), with no difference between the two groups. Conversely, there was a difference in the TDI and speckle-tracking indices, so that the group achieving a lower $\mathrm{VO}_{2 \text { peak }}$ showed a $10 \%$ lower baseline S' and GLS values at rest.

\section{Cardiopulmonary exercise test}

All patients performed a maximal exercise test, as defined by the maximal respiratory exchange ratio steadily greater than 1.05 at peak exercise according to guidelines [1]. The group with reduced exercise capacity achieved a $24 \%$ lower $\mathrm{VO}_{2 \text { peak }}$ and a $10 \%$ lower peak workload and peak heart rate, while the mean systolic and diastolic blood pressure values were comparable throughout the test. We observed similar results at the sensitivity analysis to exclude drug-related chronotropic insufficiency, observing similar results (see Additional file 1: Table S4); however, these data should be interpreted considering the decrease in sample size. No difference was identified in ventilatory or gas exchange parameters, while the anaerobic threshold (AT) was reached earlier in the subjects with effort intolerance both in absolute terms, as well as when expressed as $\%$ of $\mathrm{VO}_{2 \text { peak }}$. The group with reduced exercise capacity showed a higher prevalence of chronotropic incompetence, a lower $\mathrm{VO}_{2}$ /workload slope, a reduced oxygen pulse at peak, as well as an impaired peripheral oxygen extraction $\left[(\mathrm{a}-\mathrm{v}) \Delta \mathrm{O}_{2}\right]$ at peak. These results are reported in Table 2 and in Fig. 1.

\section{Exercise echocardiography}

During exercise, cardiac output (CO), LVEF, S, GLS, and E/e' all increased linearly with the workload. A reduced systolic reserve was observed in the group with effort intolerance in the form of: lower prevalence of subjects with a normal contractility reserve (i.e. an increase in LVEF $>7.5 \%$ ), reduced $\Delta S^{\prime}$ (peak vs baseline), as well as in reduced early (4 min of exercise) GLS and GLS change from baseline $(\Delta \mathrm{GLS})$. LV diastolic indices, stroke volume, and cardiac output did not differ between the two groups throughout the iCPET test, as well as the right heart indices did not change throughout the test (TAPSE, sPAP, TAPSE/sPAP, TAPSE/CO) (Table 2 and Fig. 1). 
Table 1 Baseline characteristics of the study population

\begin{tabular}{|c|c|c|c|c|}
\hline & \multirow{2}{*}{$\begin{array}{l}\text { All patients } \\
(n=88)\end{array}$} & \multicolumn{2}{|c|}{ Effort Intolerance } & \multirow[t]{2}{*}{ p value } \\
\hline & & $\begin{array}{l}\text { Yes } \\
(n=48)\end{array}$ & $\begin{array}{l}\text { No } \\
(n=40)\end{array}$ & \\
\hline \multicolumn{5}{|l|}{ Demographic and clinical data } \\
\hline Male gender $(n, \%)$ & $71(81 \%)$ & $42(88 \%)$ & $29(73 \%)$ & ns \\
\hline Age (years) & $63.8 \pm 9.2$ & $62.0 \pm 9.4$ & $65.9 \pm 8.5$ & 0.0446 \\
\hline BMI $\left(\mathrm{kg} / \mathrm{m}^{2}\right)$ & $29.0 \pm 4.7$ & $29.8 \pm 5.4$ & $28.0 \pm 3.6$ & ns \\
\hline Systolic BP (mmHg) & $135.9 \pm 15.5$ & $136.5 \pm 16.0$ & $135.1 \pm 15.1$ & ns \\
\hline Diastolic BP (mmHg) & $83.1 \pm 9.6$ & $83.3 \pm 9.7$ & $82.9 \pm 9.7$ & ns \\
\hline Alcohol (n, \%) & $5(6 \%)$ & $3(6 \%)$ & $2(5 \%)$ & ns \\
\hline Smoke $(n, \%)$ & $14(16 \%)$ & $10(21 \%)$ & $4(10 \%)$ & ns \\
\hline Hypertension (n, \%) & $67(76 \%)$ & $38(79 \%)$ & $30(73 \%)$ & ns \\
\hline Dyslipidemia (n, \%) & $66(75 \%)$ & $35(73 \%)$ & $31(76 \%)$ & ns \\
\hline Duration of diabetes (years) & $9.3 \pm 8.0$ & $9.9 \pm 7.7$ & $8.6 \pm 8.4$ & ns \\
\hline \multicolumn{5}{|l|}{ Therapy } \\
\hline ACEi/ARBs $(n, \%)$ & $56(63 \%)$ & $30(63 \%)$ & $25(63 \%)$ & ns \\
\hline Beta-blockers (n, \%) & $23(26 \%)$ & $12(25 \%)$ & $11(27 \%)$ & ns \\
\hline Mineralocortic. Rec. Ant. (n, \%) & $3(3 \%)$ & $2(4 \%)$ & $1(2 \%)$ & ns \\
\hline Hydrochlorothyazide (n, \%) & $13(15 \%)$ & $6(13 \%)$ & $7(17 \%)$ & ns \\
\hline Furosemide $(\mathrm{n}, \%)$ & $3(3 \%)$ & $3(6 \%)$ & $0(0 \%)$ & ns \\
\hline Statin (n, \%) & $63(71 \%)$ & $32(67 \%)$ & $30(76 \%)$ & ns \\
\hline Metformin, n (\%) & $76(85 \%)$ & $41(85 \%)$ & $34(85 \%)$ & ns \\
\hline GLP1R-A (n, \%) & $2(2 \%)$ & $1(2 \%)$ & $1(2 \%)$ & ns \\
\hline DPP4i (n, \%) & $2(2 \%)$ & $2(4 \%)$ & $0(0 \%)$ & ns \\
\hline SGLT2i $(n, \%)$ & $0(0 \%)$ & $0(0 \%)$ & $0(0 \%)$ & ns \\
\hline Insulin (n, \%) & $14(16 \%)$ & $10(21 \%)$ & $4(10 \%)$ & ns \\
\hline \multicolumn{5}{|l|}{ Biohumoral data } \\
\hline $\mathrm{HbA}_{1 \mathrm{c}}(\mathrm{mmol} / \mathrm{mol})$ & $56.8 \pm 10.4$ & $56.9 \pm 11.1$ & $56.5 \pm 9.7$ & ns \\
\hline Cholesterol (mg/dL) & $163.6 \pm 18.4$ & $157.6 \pm 39.2$ & $172.3 \pm 35.4$ & ns \\
\hline $\mathrm{HDL}-\mathrm{c}(\mathrm{mg} / \mathrm{dL})$ & $49.5 \pm 13.3$ & $46.9 \pm 11.2$ & $53.2 \pm 14.4$ & 0.0283 \\
\hline LDL-c (mg/dL) & $100.0 \pm 32.9$ & $94.6 \pm 33.2$ & $107.5 \pm 31.1$ & ns \\
\hline Ttriglycerides (mg/dL) & $129.9 \pm 57.5$ & $137.3 \pm 57.6$ & $119.7 \pm 56.6$ & ns \\
\hline Hemoglobin (g/dL) & $14.3 \pm 1.3$ & $14.2 \pm 1.4$ & $14.3 \pm 1.1$ & ns \\
\hline Creatinin (mg/dL) & $0.89 \pm 0.22$ & $0.89 \pm 0.20$ & $0.90 \pm 0.24$ & ns \\
\hline eGFR (mL/min/1.73mq) & $86.5 \pm 15.8$ & $89.5 \pm 17.1$ & $82.9 \pm 13.6$ & 0.0476 \\
\hline Uric acid (mg/dL) & $5.39 \pm 1.39$ & $5.49 \pm 1.61$ & $5.22 \pm 1.10$ & ns \\
\hline ACR (mg/g) & $6.0(0.0-14.3)$ & $5.8(1.9-27.6)$ & $6.1(0.0-9.9)$ & ns \\
\hline CRP (mg/dL) & $0.278 \pm 0.450$ & $0.360 \pm 0.590$ & $0.193 \pm 0.189$ & ns \\
\hline $\mathrm{BNP}(\mathrm{pg} / \mathrm{mL})$ & $16(10-33)$ & $14(10-37)$ & $16(10-29)$ & ns \\
\hline \multicolumn{5}{|l|}{ Vascular and endothelial data } \\
\hline RHI endoPAT & $0.62 \pm 0.28$ & $0.63 \pm 0.25$ & $0.60 \pm 0.32$ & ns \\
\hline CAVI mean & $9.32 \pm 1.59$ & $9.01 \pm 1.69$ & $9,67 \pm 1.40$ & ns \\
\hline
\end{tabular}

The study population is reported as a whole and divided in two groups based on the achievement of a peak oxygen uptake $>80 \%$ of the maximal theorical oxygen uptake. P values were calculated with a student t-test and were reported as "ns" if non significant

\section{Regression analysis}

According to the Fick's equation, whole-body oxygen uptake is determined by $\mathrm{CO}$ and $\Delta(\mathrm{a}-\mathrm{v}) \mathrm{O}_{2}$; in our study, peripheral oxygen extraction explains the impaired exercise capacity (Fig. 2). Therefore, we focused the regression analysis on $\Delta(\mathrm{a}-\mathrm{v}) \mathrm{O}_{2}$. In the whole population, univariate determinants of $\Delta(\mathrm{a}-\mathrm{v})$ $\mathrm{O}_{2}$ at peak were: sex, hemoglobin levels, peak $\mathrm{CO}$, peak systemic vascular resistance, peak mean arterial pressure, GLS at $4 \mathrm{~min}$ and $\Delta$ GLS. In a multiple regression 
Table 2 Results of cardiopulmonary exercise test and exercise echocardiography

\begin{tabular}{|c|c|c|c|c|c|}
\hline & \multirow{2}{*}{$\begin{array}{l}\text { All patients } \\
(n=88)\end{array}$} & \multicolumn{2}{|c|}{ Effort Intolerance } & \multirow[t]{2}{*}{$p$ value } & \multirow[t]{2}{*}{ "Adjusted" p value } \\
\hline & & $\begin{array}{l}\text { Yes } \\
(n=48)\end{array}$ & $\begin{array}{l}\text { No } \\
(n=40)\end{array}$ & & \\
\hline \multicolumn{6}{|l|}{ Cardiopulmonary exercise test } \\
\hline Workload (W) & $118 \pm 30$ & $113 \pm 25$ & $126 \pm 34$ & 0.0460 & $<0.0001$ \\
\hline Time of effort (min) & $11.4 \pm 2.0$ & $10.8 \pm 1.8$ & $12.0 \pm 2.0$ & 0.0050 & 0.0008 \\
\hline HR rest (bpm) & $79.9 \pm 13.6$ & $80.5 \pm 12.9$ & $79.3 \pm 14.6$ & ns & ns \\
\hline HR peak (bpm) & $132.9 \pm 18.6$ & $129.2 \pm 19.0$ & $137.4 \pm 17.2$ & 0.0361 & 0.0015 \\
\hline HR peak (\%max) & $86.1 \pm 12.0$ & $82.6 \pm 12.4$ & $90.2 \pm 10.2$ & 0.0023 & 0.0015 \\
\hline HR reserve (bpm) & $74.7 \pm 15.7$ & $76.1 \pm 14.6$ & $73.0 \pm 16.9$ & ns & ns \\
\hline Chronotr. incomp. $(n, \%)$ & $46(53 \%)$ & $34(71 \%)$ & $12(30 \%)$ & 0.0001 & 0.0005 \\
\hline MBP rest $(\mathrm{mmHg})$ & $102.9 \pm 10.3$ & $103.3 \pm 10.9$ & $102.5 \pm 9.6$ & ns & ns \\
\hline MBP peak $(\mathrm{mmHg})$ & $146.5 \pm 16.3$ & $146.9 \pm 18.2$ & $146.1 \pm 14.0$ & ns & ns \\
\hline RER peak & $1.08 \pm 0.06$ & $1.09 \pm 0.07$ & $1.07 \pm 0.06$ & ns & ns \\
\hline $\mathrm{VO}_{2} /$ work slope & $10.5 \pm 1.5$ & $9.9 \pm 1.2$ & $11.2 \pm 1.4$ & $<0.0001$ & $<0.0001$ \\
\hline $\mathrm{VO}_{2}$ rest $(\mathrm{mL} / \mathrm{min} / \mathrm{kg})$ & $4.1 \pm 9.1$ & $3.7 \pm 1.2$ & $4.6 \pm 1.3$ & 0.0015 & 0.0005 \\
\hline $\mathrm{VO}_{2} \mathrm{AT}(\mathrm{mL} / \mathrm{min} / \mathrm{kg})$ & $16.2 \pm 4.9$ & $13.7 \pm 2.7$ & $19.5 \pm 5.2$ & $<0.0001$ & $<0.0001$ \\
\hline $\mathrm{VO}_{2} \mathrm{AT}\left(\%\right.$ peakVO $\left.\mathrm{V}_{2}\right)$ & $84.5 \pm 11.9$ & $81.5 \pm 13.7$ & $88.8 \pm 7.7$ & 0.0115 & 0.0047 \\
\hline $\mathrm{VO}_{2}$ peak $(\mathrm{mL} / \mathrm{min} / \mathrm{kg})$ & $18.8 \pm 5.1$ & $16.45 \pm 3.19$ & $21.69 \pm 5.39$ & $<0.0001$ & $<0.0001$ \\
\hline $\mathrm{VO}_{2}$ peak $\left(\% \mathrm{VO}_{2 \max }\right)$ & $79.0 \pm 17.0$ & $66.7 \pm 8.8$ & $93.6 \pm 11.9$ & $<0.0001$ & $<0.0001$ \\
\hline VE $/ \mathrm{VCO}_{2}$ slope & $27.5 \pm 3.8$ & $27.2 \pm 4.1$ & $27.8 \pm 3.3$ & ns & ns \\
\hline VDNT (\%) & $15.6 \pm 4.1$ & $16.0 \pm 3.9$ & $15.2 \pm 4.4$ & ns & ns \\
\hline $\mathrm{O}_{2}$ pulse peak (mL/bpm) & $11.7 \pm 2.8$ & $11.3 \pm 2.5$ & $12.3 \pm 3.0$ & ns & $<0.0001$ \\
\hline $\mathrm{O}_{2}$ pulse peak (\%max) & $94.2 \pm 18.0$ & $84.3 \pm 14.0$ & $106.0 \pm 15.0$ & $<0.0001$ & $<0.0001$ \\
\hline$A \vee \mathrm{O}_{2}$ diff rest $(\mathrm{mL} / \mathrm{dL})$ & $6.5 \pm 2.3$ & $6.1 \pm 2.4$ & $6.9 \pm 2.3$ & ns & 0.0218 \\
\hline $\mathrm{AV} \mathrm{O}_{2}$ diff peak $(\mathrm{mL} / \mathrm{dL})$ & $11.9 \pm 3.2$ & $11.3 \pm 3.1$ & $12.7 \pm 3.3$ & 0.0399 & 0.0002 \\
\hline \multicolumn{6}{|l|}{ Exercise echocardiography } \\
\hline $\mathrm{EDVi}\left(\mathrm{mL} / \mathrm{m}^{2}\right)$ & $51.0 \pm 11.1$ & $51.7 \pm 10.5$ & $51.0 \pm 13.0$ & ns & ns \\
\hline LVMi $\left(\mathrm{g} / \mathrm{m}^{2}\right)$ & $86.3 \pm 16.6$ & $86.6 \pm 14.4$ & $87.4 \pm 20.8$ & ns & ns \\
\hline LAVi $\left(\mathrm{mL} / \mathrm{m}^{2}\right)$ & $24.7 \pm 7.6$ & $24.5 \pm 8.2$ & $25.5 \pm 7.5$ & ns & ns \\
\hline SV rest $(\mathrm{mL})$ & $69.1 \pm 14.8$ & $69.5 \pm 13.3$ & $68.6 \pm 13.0$ & ns & ns \\
\hline SV peak $(\mathrm{mL})$ & $102.1 \pm 22.8$ & $103.3 \pm 26.6$ & $100.7 \pm 22.1$ & ns & ns \\
\hline CO rest $(\mathrm{L} / \mathrm{min})$ & $5.5 \pm 1.2$ & $5.5 \pm 1.3$ & $5.4 \pm 1.2$ & ns & ns \\
\hline CO peak (L/min) & $13.7 \pm 3.7$ & $13.4 \pm 3.7$ & $14.0 \pm 3.8$ & ns & ns \\
\hline LVEF rest (\%) & $58.9 \pm 4.3$ & $58.6 \pm 0.7$ & $58.6 \pm 1.0$ & ns & ns \\
\hline LVEF peak (\%) & $67.6 \pm 5.6$ & $66.5 \pm 6.1$ & $68.9 \pm 4.8$ & ns & ns \\
\hline$\triangle \mathrm{EF}$ & $8.6 \pm 3.7$ & $8.0 \pm 4.1$ & $9.5 \pm .31$ & ns & 0.0412 \\
\hline Contractility reserve $(n, \%)$ & $53(60 \%)$ & $23(26 \%)$ & $30(34 \%)$ & 0.0154 & 0.0386 \\
\hline GLS rest (\%) & $16.3 \pm 2.6$ & $15.7 \pm 2.5$ & $17.0 \pm 2.6$ & 0.0321 & ns \\
\hline GLS $4 \min (\%)$ & $18.4 \pm 3.0$ & $17.5 \pm 2.9$ & $19.5 \pm 2.8$ & 0.0044 & 0.0048 \\
\hline$\Delta \mathrm{GLS}$ & $2.1 \pm 1.5$ & $1.7 \pm 1.5$ & $2.5 \pm 1.8$ & 0.0293 & 0.0093 \\
\hline $\mathrm{S}^{\prime}$ mean rest $(\mathrm{cm} / \mathrm{sec})$ & $9.2 \pm 1.8$ & $8.8 \pm 1.8$ & $9.6 \pm 1.7$ & 0.0364 & ns \\
\hline $\mathrm{S}^{\prime}$ mean peak $(\mathrm{cm} / \mathrm{s})$ & $14.3 \pm 3.0$ & $13.5 \pm 2.8$ & $15.2 \pm 3.0$ & 0.0085 & 0.0006 \\
\hline$\Delta S^{\prime}$ mean & $5.1 \pm 2.1$ & $4.7 \pm 1.9$ & $5.6 \pm 2.3$ & ns & 0.0023 \\
\hline E/e'rest (cm/s) & $8.3 \pm 2.2$ & $8.6 \pm 2.3$ & $8.0 \pm 2.2$ & ns & ns \\
\hline E/e'peak (cm/sec) & $8.6 \pm 2.0$ & $8.7 \pm 2.1$ & $8.4 \pm 1.9$ & ns & ns \\
\hline SVR rest (dyne*s/cm) & $1,583 \pm 367$ & $1,578 \pm 383$ & $1,588 \pm 353$ & ns & ns \\
\hline SVR peak (dyne*s/cm) & $911 \pm 218$ & $932 \pm 230$ & $885 \pm 203$ & ns & ns \\
\hline TAPSE/sPAP peak & $0.95 \pm 0.23$ & $0.96 \pm 0.21$ & $0.94 \pm 0.26$ & ns & ns \\
\hline TAPSE/CO peak & $2.24 \pm 0.62$ & $2.33 \pm 0.64$ & $2.12 \pm 0.58$ & ns & ns \\
\hline
\end{tabular}

The whole population and the two groups divided by the presence or absence of effort intolerance, are reported. $\mathrm{P}$ values were calculated as Student's t test for comparisons of the means of the two groups, and "adjusted" $p$ values were calculated after adjustment for age, sex, and BMI 

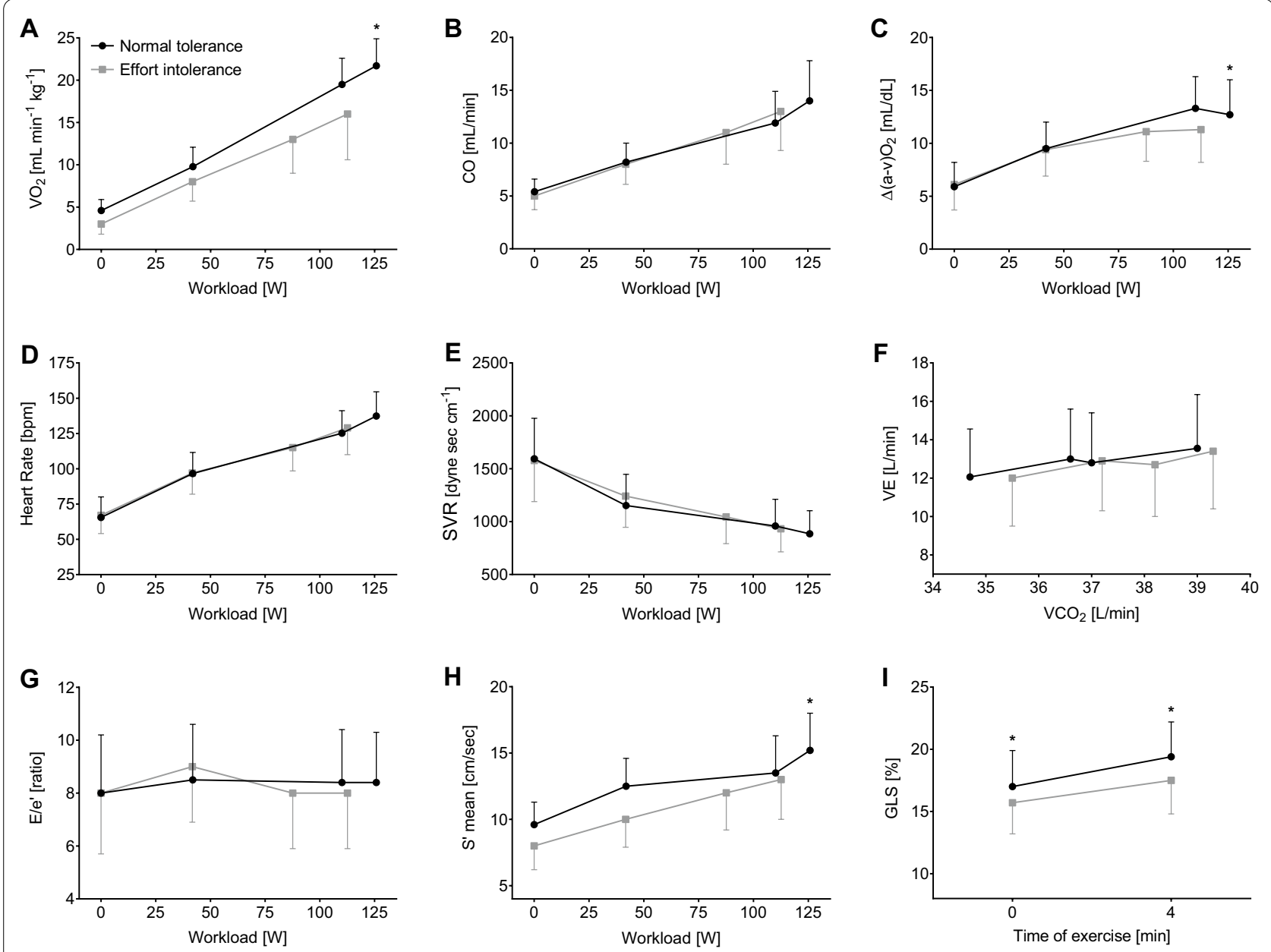

Fig. 1 Graphic representation of nine key variables obtained during imaging-cardiopulmonary exercise test. Grey lines represent the group with effort intolerance, black lines represent the control group. Significant differences are highlighted by a star $\left(^{*}\right)$

model, only male sex (st- $\beta 0.35, \mathrm{p}=0.0002$ ), hemoglobin levels (st- $\beta$ 0.22, $\mathrm{p}=0.0133$ ), and $\Delta \mathrm{GLS}$ (st- $\beta$ $0.21, \mathrm{p}=0.0486)$ were independent predictors of peak $\Delta(\mathrm{a}-\mathrm{v}) \mathrm{O}_{2}$ (see Table 3$)$.

To gain insight on the link between reduced peak oxygen utilization and systolic dysfunction, linear regression analyses were performed on the two corresponding sets of variables in the whole population (Fig. 3). Significant positive linear correlations were found between $S^{\prime}$ at peak and $\mathrm{VO}_{2 \text { peak }}$ (Panel A), as well as between $\Delta \mathrm{S}^{\prime}$ and $\mathrm{VO}_{2 \text { peak }}$ (panel B), between GLS at 4 min and $\mathrm{VO}_{2 \text { peak }}$ (panel C) and $\triangle$ GLS and $\mathrm{VO}_{2 \text { peak }}$ (panel D). Also, we observed a significant correlations between $\Delta(\mathrm{a}-\mathrm{v}) \mathrm{O}_{2}$ and GLS at 4 min (panel E) and change in GLS (Panel F).

\section{Discussion}

\section{Effort intolerance in type 2 diabetes}

We examined 88 older adults with well-controlled and uncomplicated T2D undergoing a maximal iCPET.
The observed value of $\mathrm{VO}_{2 \text { peak }}$ in the whole population $(18 \mathrm{~mL} / \mathrm{kg} / \mathrm{min}$ ) falls far below the reference values for the general population of this age group (women $31 \mathrm{~mL} /$ $\mathrm{kg} / \mathrm{min}$; men $39 \mathrm{~mL} / \mathrm{kg} / \mathrm{min}$ ) [26], confirming previous reports indicating poor exercise capacity in T2D subjects [4]. An identical mean value of $\mathrm{VO}_{2 \text { peak }}(18.0 \pm 6.6 \mathrm{~mL} /$ $\mathrm{min} / \mathrm{kg}$ ) has been recently reported in a larger and even younger (by 10 years) cohort of 224 asymptomatic subjects with T2D, falling into the lower $10 \%$ of the agematched male general population distribution and the lower $20 \%$ of female general population [27]. Exercise intolerance, defined by $\mathrm{VO}_{2 \text { peak }}$ below $80 \%$ of the predicted value according to Wasserman equation, is widely used to define negative prognosis in subjects suffering from heart disease [1]; still, it was present in most (55\%) of our study population despite the absence of either vascular and autonomic diabetic complications, criteria for a definite diagnosis of HF, or any detectable significant cardiac impairment at resting assessment. The prevalence 


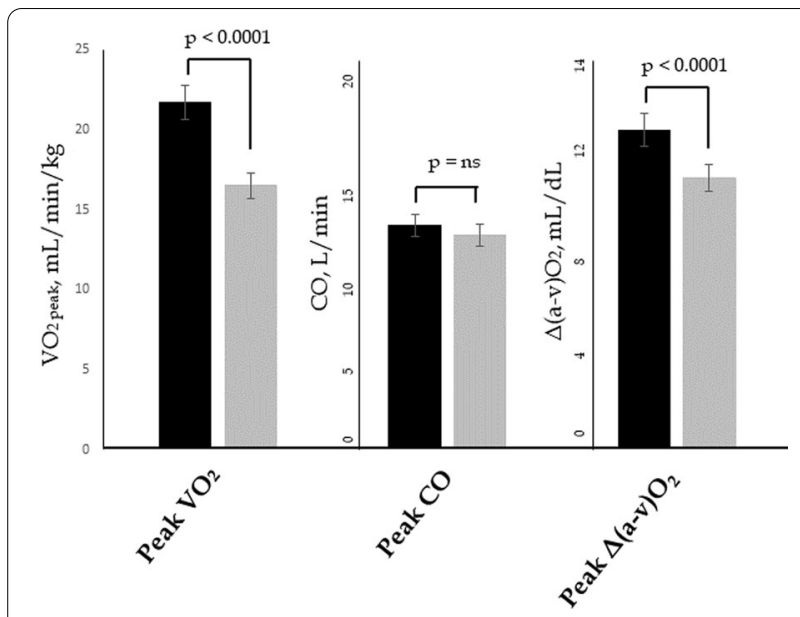

Fig. 2 Linear regressions between systolic indices, peripheral oxygen extraction, and peak oxygen uptake. A significant positive linear correlation exists between $\mathrm{S}^{\prime}(\mathbf{A})$ at peak/change in $\mathrm{S}^{\prime}$ and $\mathrm{VO}_{2 \text { peak }}$ (B), as well as between $\mathrm{GLS}$ at 4 min and $\mathrm{VO}_{\text {2peak }}(\mathbf{C})$ and change in $\mathrm{GLS}$ and $\mathrm{VO}_{\text {2peak }}$ (D). A positive linear correlation was also observed between $\triangle(a-v) \mathrm{O}_{2}$ and GLS at 4 min (E) and change in GLS (F)

of this severe condition in uncomplicated T2D was not reported in previous studies, wherein the severity of effort intolerance has probably been underestimated. Indeed, the subjects in our cohort with effort intolerance show $\mathrm{VO}_{2 \text { peak }}$ values that are commonly found in patients with overt HF, a population wherein such a reduced $\mathrm{VO}_{2 \text { peak }}$ portends a rather poor prognosis [28].

The study population was homogeneous in demographic parameters, glycemic control, duration of diabetes, cardio-active and glucose-lowering therapy, vascular and endothelial function parameters, as well as the prevalence of comorbidities (Table 1). It is thus very difficult to predict effort intolerance based on the resting clinical phenotype alone. The difference in HDL cholesterol was small and seemingly driven by the slightly higher prevalence of male and overweight subjects in the group with low $\mathrm{VO}_{2 \text { peak. }}$. This, together with the presence of a small difference in age, prompted the decision to verify the differences in iCPET data after adjusting for age, sex and BMI (Table 2). Since effort intolerance is the hallmark of HF irrespective of LVEF [2], and that cardiorespiratory fitness is known to be a strong predictor of incident HFpEF in the T2D population [6], we sought to determine the associated alterations and mechanisms underpinning the reduced $\mathrm{VO}_{2 \text { peak }}$ in $\mathrm{T} 2 \mathrm{D}$ patients to gain insight on the earliest defects at the bases of the their higher HF vulnerability. Previous findings reported early development of fatigue in T2D as a perceived limitation of force-generating capacity that requires higher intensity of effort that might eventually reduce the exercise duration, and that can be highlighted by an early appearance
Table 3 Determinants of peripheral oxygen extraction

\begin{tabular}{|c|c|c|c|c|}
\hline \multirow[b]{2}{*}{ Variable } & \multicolumn{2}{|c|}{ Univariate } & \multicolumn{2}{|c|}{ Multivariate } \\
\hline & st- $\beta$ & $\mathbf{p}$ & st- $\beta$ & $\mathbf{p}$ \\
\hline Age & 0.01 & ns & & \\
\hline Sex & 0.07 & 0.0138 & 0.35 & 0.0002 \\
\hline BMl & 0.01 & ns & & \\
\hline Duration of diabetes & -0.01 & ns & & \\
\hline $\mathrm{HbA}_{1 \mathrm{c}}$ & -0.04 & ns & & \\
\hline Smoke & 0.02 & ns & & \\
\hline Hypertension & 0.02 & ns & & \\
\hline metformin & -0.01 & ns & & \\
\hline Creatinine & 0.02 & ns & & \\
\hline ACR $(\log )$ & -1.02 & ns & & \\
\hline PCR (log) & -0.50 & ns & & \\
\hline Hemoglobin & 0.70 & 0.0103 & 0.22 & 0.0133 \\
\hline RHI endoPAT & -0.06 & ns & & \\
\hline CAVI & 0.20 & ns & & \\
\hline$A B \mid$ & 0.08 & ns & & \\
\hline MBP peak & -0.05 & 0.0175 & -0.02 & ns \\
\hline SVR peak & 0.01 & $<0.0001$ & 0.01 & ns \\
\hline CO peak & -0.52 & $<0.0001$ & -0.30 & ns \\
\hline LVEF rest & -0.01 & ns & & \\
\hline LVEF peak & 0.01 & ns & & \\
\hline$\triangle$ LVEF & 0.10 & ns & & \\
\hline GLS rest & 0.12 & ns & & \\
\hline GLS 4 min & 0.34 & 0.0060 & 0.10 & ns \\
\hline$\triangle \mathrm{GLS}$ & 0.19 & $<0.0001$ & 0.21 & 0.0486 \\
\hline S'rest & 0.06 & ns & & \\
\hline S'peak & 0.06 & ns & & \\
\hline$\triangle S^{\prime}$ & 0.16 & ns & & \\
\hline E/e' peak & 0.12 & ns & & \\
\hline VE $\mathrm{NCO}_{2}$ slope & -0.06 & ns & & \\
\hline
\end{tabular}

of exhaustion during exercise and in higher fatigue with respect to controls at any given workload, even when adjusted for the reduced $\mathrm{VO}_{2 \text { peak }}[29,30]$. Still, the reasons for the decreased exercise tolerance are far from being clear, possibly encompassing any combination of myocardiogenic, skeletal myogenic, vasculogenic, or neurogenic determinants [4]; we sought to determining the associated alterations in the different organs and systems.

\section{Mechanisms of effort intolerance in type 2 diabetes}

Our first finding is that effort intolerance is not due to a defect in mechanical efficiency (as was suggested for obese individuals $[31,32]$ ), given that the slope of $\mathrm{VO}_{2} \mathrm{vs}$ work-rate is steeper in subjects with preserved exercise tolerance (Fig. 1) and that we can exclude an impairment in ventilatory parameters. A reduced $\mathrm{O}_{2}$ supply could be related to central (lung and/or heart) or peripheral (hematologic, vascular, or mitochondrial) impairment 

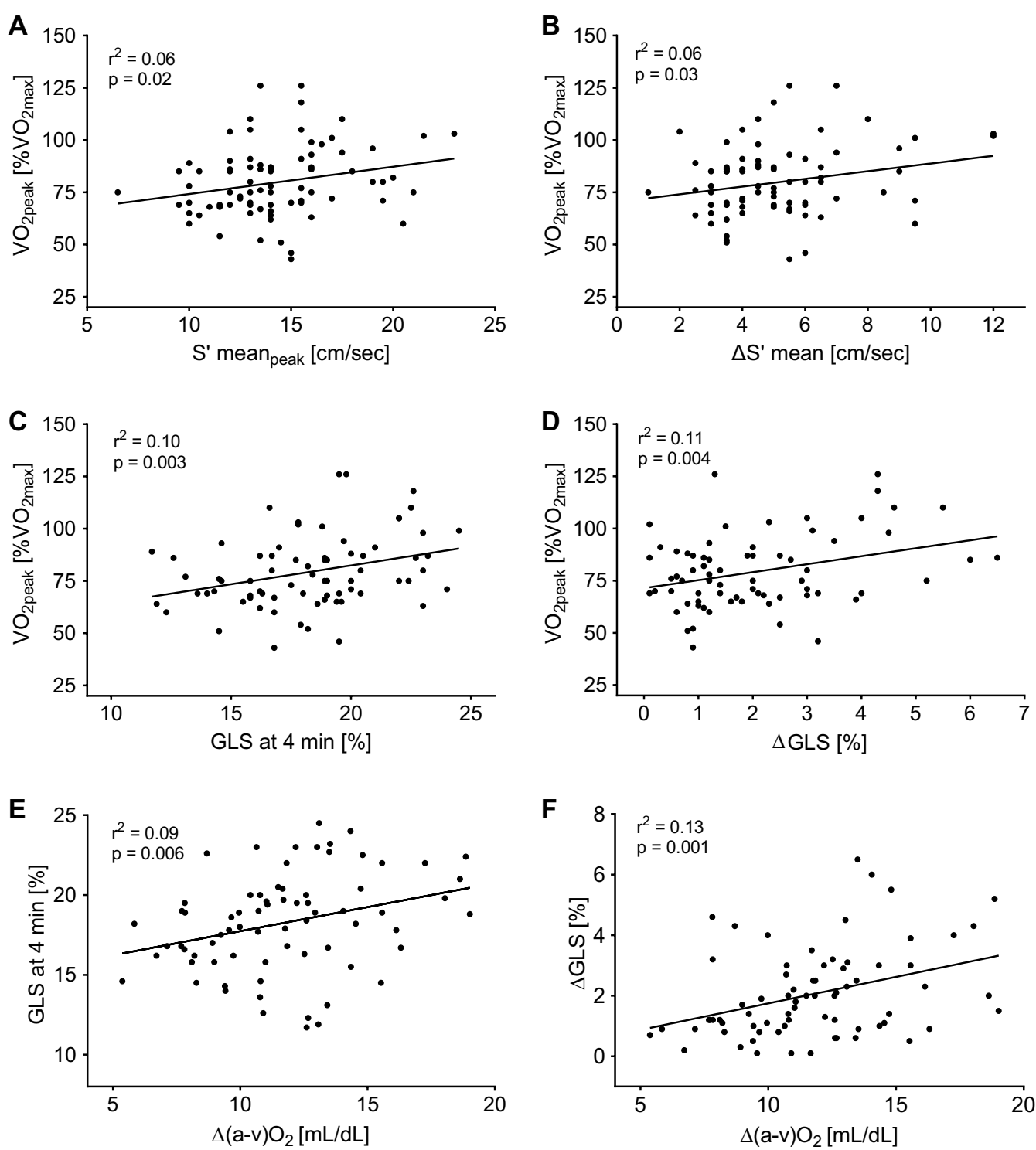

Fig. 3 Determinants of peak oxygen uptake according to Fick's principle. $\mathrm{VO}_{2}$ is determined by cardiac output (CO) and peripheral oxygen extraction $\left(\Delta(\mathrm{a}-\mathrm{v}) \mathrm{O}_{2}\right)$. The $\mathrm{p}$ value for the difference between the two study groups is shown on top of the diagrams

[4]. We excluded lung disease, as all the patients underwent spirometry before exercise, whilst hematologic diseases were excluded after analysis of blood exams before enrollment. Then, imaging-CPET provides the opportunity to dissect the different components of the Fick's equation, thanks to the possibility of measuring stroke volume with the simultaneous echocardiographic assessment. According to the Fick's principle, a reduced peripheral oxygen extraction explains the impaired cardiopulmonary function in our population (Fig. 3). Previous studies have reported either a reduced or a normal peripheral extraction in T2D [33, 34]. Notably, both the study by Baldi et al. [33] and the more recent one by Kobayashi [35] performed in a similar population of asymptomatic T2D patients confirm our findings of a normal cardiac output with a $\Delta(\mathrm{a}-\mathrm{v}) \mathrm{O}_{2}$ that was reduced by $20 \%$ compared to the control group and that correlated with the reduced $\mathrm{VO}_{2 \text { peak }}$. Notably, in line with our findings, the Authors conclude that a reduced peripheral oxygen extraction might be regarded as a limitation to wholebody oxygen uptake. The older study showing normal $\Delta(\mathrm{a}-\mathrm{v}) \mathrm{O}_{2}$ was conducted in a very small group of female adolescents [34], thus with poor clinical applicability. 
The two groups of our study did not differ in biohumoral values, endothelial function, indices of pulmonary function, diastolic function indices, right heart indices, mean arterial pressure, and systemic vascular resistances throughout the entire iCPET. The subjects with effort intolerance showed higher prevalence of chronotropic incompetence. The large difference, however, is driven by the fact the patients of our study group fall close to the $80 \%$ threshold (mean HR peak\%: $86.1 \%$ ) thus a small difference in peak HR generates a major recruitment of subject with a diagnosis of chronotropic incompetence. In quantitative terms, the difference between the groups was small; subjects with effort intolerance exploited their HR reserve only $8 \%$ less than the others (82.6 vs $90.2 \%$ ) with a difference in peak HR of just 8 beats/minute (129 vs $137 \mathrm{bpm}$ ). If we also consider that no subject had evidence of CAN at conventional tests and, more importantly, that HR kinetics and peak $\mathrm{CO}$ were superimposable in the two groups throughout the whole iCPET, it is unlikely that chronotropic incompetence is the cause of effort intolerance in our patient; it might rather be the consequence of their lower fitness.

Whilst crude indices of systolic performance such as SV, CO and LVEF were not different between the two study groups, less load-dependent indices ( $S^{\prime}$ and GLS) showed a gradient that was evident both in resting conditions and in exercise-induced changes. It is widely known that a reduced baseline GLS is an early marker of LV subclinical systolic dysfunction, being present both in HFpEF patients irrespective of the diabetic state [24] and in T2D subjects without HF $[36,37]$ - where it also predicts incident HF [38]. Our findings confirm most previous reports (although not all [39]) describing reduced S' velocity of the mitral annulus measured through tissue Doppler in patients with T2D during exercise [40-42], an observation that was also related to myocardial fibrosis as measured though cardiac magnetic resonance [43]. Given the large prevalence of diastolic dysfunction in T2D subjects [38] and the results of a recent report by Gulsin et al. [44], we were surprised not to see alteration in E/e' in our population with effort intolerance, neither at rest nor during exercise. In the work of Gulsin and coll., however, diastolic indices were not measured during exercise, and the association was essentially driven by a minority of subjects with a baseline E/e' > of 12.5 , and in the whole population the effect size was small with +1 units of E/e' justifying $-0.3 \mathrm{ml} / \mathrm{kg} / \mathrm{min}$ of $\mathrm{VO}_{2 \text { peak }}$. Based on our data, diastolic dysfunction is not relevant for explaining effort intolerance in T2D.

\section{Determinants of peripheral oxygen extraction}

In multivariate analysis, the determinants of $\Delta(\mathrm{a}-\mathrm{v}) \mathrm{O}_{2}-$ the main factor explaining the reduced $\mathrm{VO}_{2 \text { peak }}$ in our population-were sex, hemoglobin levels, and $\Delta \mathrm{GLS}$ (Table 3). This confirms previous observations on the sex-related differences in effort tolerance and possibly the different risk of HF development seen between T2D males and females [45]. It also supports the deterministic role of hemoglobin in ambient oxygen availability [1]. At rest, diabetic individuals show reduced ATP release from red blood cells in response to hemoglobin desaturation activated through endothelial purinergic receptors that trigger nitric oxide-dependent and independent arteriolar vasodilation, and that significantly impacts on muscle blood flow [46]; however, its relevance during exercise in unknown. Interestingly, SGLT-2 inhibitors, which protect T2D patients from HF incidence and decompensation through unknown mechanisms, significantly rise hemoglobin as a side effect [47]. Since SGLT-2 inhibitors have been recently demonstrated to ameliorate aerobic fitness in T2D subjects both without HF [48] and with HFpEF [49], one can speculate that the hemoconcentration with increased hemoglobin obtained with their pharmacological effect might increase $\Delta(\mathrm{a}-\mathrm{v}) \mathrm{O}_{2}$ and partly explain the increased whole-body oxygen uptake. Finally, the strength of the correlation between subclinical systolic dysfunction to peak $\Delta(\mathrm{a}-\mathrm{v}) \mathrm{O}_{2}$ and $\mathrm{VO}_{2 \text { peak }}$ is a novel finding suggesting a strong link between skeletal and cardiac muscle pathology in T2D. This relationship was previously demonstrated in animal models of T2D [50], while in humans previous studies have reported either a reduced GLS or S' at rest [51], reduced longitudinal systolic reserve [40], or reduced $\Delta(\mathrm{a}-\mathrm{v}) \mathrm{O}_{2}$ in T2D subjects with effort intolerance [33], but none has reported a direct relationship between peripheral oxygen extraction and systolic indices, neither at rest nor during exercise.

\section{Clinical value}

Taken together, the results of the present study suggest a myogenic limitation of whole-body oxygen uptake in T2D limiting exercise tolerance, with a tight interplay between myocardial and skeletal muscles. Whether this is secondary to a reduced number of mitochondria, a mitochondrial functional impairment, altered myofibrillar structure and/or composition, muscle microvasculature, or to systemic regulators of muscle perfusion [4] goes beyond the purpose of this study. However, the lack of relationships with total peripheral resistances and endothelial function supports a primitive muscle cell impairment involving both skeletal and myocardial muscle. The lower anaerobic threshold, also when expressed in terms of $\% \mathrm{VO}_{2 \text { peak }}$, indicates a reduced aerobic capacity and strongly supports the hypothesis of a mitochondrial defect either in number or in function, as previously observed in this population [52, 53]. The observation that exercise training can increase whole-body oxygen 
consumption through an amelioration of skeletal muscle energetics further sustains this point $[54,55]$.

The combination of reduced $\mathrm{VO}_{2 \text { peak, }} \Delta(\mathrm{a}-\mathrm{v}) \mathrm{O}_{2}$, and GLS of the subjects with T2D and effort intolerance observed in the present study represents a phenotype which is also shared by the patients with HFpEF wherein reduced peripheral oxygen extraction and/or GLS appear as the major determinants of effort intolerance [37, 56, 57]. Being each trait less pronounced in our population, we speculate that this condition might represent an intermediate phenotype and-if eventually confirmed to be so prevalent in T2D-might explain the excess prevalence of HFpEF among these patients $[2,56]$. Of note, our population did not show diastolic dysfunction as a key determinant of effort intolerance, at least not as importantly as in HFpEF subjects [2], probably marking a further step forward towards overt HFpEF. Due to the "diabesity" pandemic and the high incidence (and costs) of HFpEF, new strategies for the early identification of the patients at risk of HFpEF are needed. In this context, the iCPET might reveal a useful screening tool [58]. Longitudinal trials evaluating the transition from T2D with effort intolerance to overt HFpEF would provide support to our hypothesis, as well as clinical intervention trials aiming at verifying whether ameliorating peripheral oxygen extraction (e.g. exercise) is possible to prevent the development of HFpEF in T2D patients.

\section{Concluding remarks}

Effort intolerance is severe and highly prevalent in uncomplicated, otherwise asymptomatic T2D, and is mainly driven by a primitive muscular impairment involving both skeletal and myocardial muscle in the form of impaired peripheral oxygen extraction and a reduced systolic reserve, despite preserved LVEF and cardiac output. These alterations closely resemble the major clinical features of HFpEF and could represent an intermediate pathological condition.

\section{Strengths and limitations}

One strength of the present study is the sample size (greater than previous reports), the multi-parametric analysis performed (previous works were focused on specific organ dysfunctions, or did not use exercise echocardiography, or considered resting variables), the careful exclusion of micro- and macrovascular complications (previous works frequently included complicated patients and highlighted the contribution of specific complications to reduced aerobic capacity), and the study of effort intolerance within the diabetic population (whilst previous works were focused on differences between diabetic and non-diabetic subjects, and the exact prevalence and mechanisms of effort intolerance within the T2D population is unknown).

We recognize some limitations of the present work. This is a single-centre, cross-sectional study with a relatively small sample size. We only focused on asymptomatic, uncomplicated T2D; therefore, the results should not be applied to different cohorts. We acknowledge that the technical challenge of acquiring echocardiography images during exercise may affect SV and $\mathrm{CO}$ measurements, despite the technique has been extensively validated and used by different groups [24]. Also $\Delta(\mathrm{a}-\mathrm{v})$ $\mathrm{O}_{2}$ was not directly measured, however our method has been extensively validated, used by several investigators [24, 25]; and, most importantly, our values are in line with observations reporting both non-invasive and invasive oxygen extraction data $[57,59]$. Our imaging protocol was performed in a semi-supine position for a better echocardiographic evaluation [13]; caution is advised to extend our results to other types of exercise (supine or upright).

\section{Abbreviations}

AT: Anaerobic threshold; BMI: Body mass index; CO: Cardiac output; CPET: Cardiopulmonary exercise test; SV: Stroke volume; E': Early left ventricular filling phase velocity; HF: Heart failure; HFpEF: Heart failure with preserved ejection fraction; HR: Heart rate; METs: Metabolic equivalents; $\mathrm{PaCO}_{2}$ : Arterial partial pressure of carbon dioxide; $\mathrm{PETCO}_{2}$ : End-tidal carbon dioxide partial pressure; $S^{\prime}$ : Peak systolic annular velocity; T2D: Type 2 diabetes mellitus; $\mathrm{VCO}_{2}$ : Carbon dioxide emission measured at the mouth; $V_{D} N_{T}$ : Physiological dead space/ tidal volume ratio; VE: Pulmonary minute ventilation; $V E / \mathrm{VCO}_{2}$ : Ventilatory equivalent for carbon dioxide or "ventilatory efficiency"; $\mathrm{VO}_{2}$ : Oxygen uptake measured at the mouth; $\mathrm{VO}_{2} / \mathrm{HR}$ : Oxygen pulse; $\mathrm{VO}_{2 \text { max }}$ : Maximal theorical oxygen uptake; $\mathrm{VO}_{2 \text { peak }}$ : Peak oxygen uptake; $\Delta(\mathrm{a}-\mathrm{v}) \mathrm{O}_{2}$ : Peripheral oxygen extraction.

\section{Supplementary Information}

The online version contains supplementary material available at https://doi. org/10.1186/s12933-021-01314-6.

Additional file 1: Table S4. Sensitivity analysis performed after having excluded all subjects taking beta-blockers. And repeating the statistical analysis as described for the whole population.

\section{Acknowledgements}

The authors are grateful to all the volunteers and the personnel of the Metabolism, Nutrition, and Atherosclerosis Lab and the Cardiopulmonary Test Lab, Department of Clinical and Experimental Medicine, University of Pisa, Italy.

\section{Authors' contributions}

LN performed the clinical and biohumoral characterization of patients, the screening of diabetic complications, kept patients' records, created the database, performed the statistical analysis, wrote the manuscript, and ideated and produced the tables and the figures. NRP performed the imaging-cardiopulmonary exercise tests, provided a substantial contribution to the interpretation of the data, and critically revised the manuscript. PS performed the screening of eligible patients, kept patients' records, and performed the screening of diabetic complications. NDB and MM performed the cardiopulmonary exercise tests, kept patients' records, and critically revised the manuscript. IF performed the cardiopulmonary exercise tests, provided 
a substantial contribution to the interpretation of the data, and critically revised the manuscript. DT performed the screening of patients, the clinical and biohumoral characterization, provided a substantial contribution to the interpretation of the data, revised the figures, and critically revised the manuscript. SM provided a substantial contribution to the interpretation of the data and critically revised the manuscript. AN conceived and designed the paper, provided a substantial contribution to the analysis and interpretation of the data, and critically revised the manuscript. All authors revised the manuscript, read and approved the final manuscript.

\section{Funding}

No funding was required for writing this paper.

\section{Availability of data and materials}

Not applicable.

\section{Declarations}

Ethics approval and consent to participate

Not applicable.

\section{Consent for publication}

All the Authors gave their consent to publication.

\section{Competing interests}

The authors have no conflict of interest to declare.

\section{Author details}

'Metabolism, Nutrition, and Atherosclerosis Laboratory, Department of Clinical and Experimental Medicine, University of Pisa, Via Savi 10, 56126 Pisa, Italy. ${ }^{2}$ Cardiopulmonary Laboratory, Department of Clinical and Experimental Medicine, University of Pisa, Pisa, Italy. ${ }^{3}$ Fondazione Toscana G. Monasterio, Pisa, Italy. ${ }^{4}$ Department of Surgical, Medical and Molecular Pathology and Critical Care Medicine, University of Pisa, Pisa, Italy.

Received: 22 March 2021 Accepted: 3 June 2021

Published online: 22 June 2021

\section{References}

1. American Thoracic S, American College of Chest P. ATS/ACCP statement on cardiopulmonary exercise testing. Am J Respir Crit Care Med. 2003;167(2):211-77.

2. Tannenbaum S, Sayer GT. Advances in the pathophysiology and treatment of heart failure with preserved ejection fraction. Curr Opin Cardiol. 2015;30(3):250-8.

3. Lehrke M, Marx N. Diabetes mellitus and heart failure. Am J Cardiol. 2017;120(1S):S37-47.

4. Nesti L, Pugliese NR, Sciuto P, Natali A. Type 2 diabetes and reduced exercise tolerance: a review of the literature through an integrated physiology approach. Cardiovasc Diabetol. 2020;19(1):134.

5. Church TS, LaMonte MJ, Barlow CE, Blair SN. Cardiorespiratory fitness and body mass index as predictors of cardiovascular disease mortality among men with diabetes. Arch Intern Med. 2005;165(18):2114-20.

6. Pandey A, Patel KV, Bahnson JL, Gaussoin SA, Martin CK, Balasubramanyam A, Johnson KC, McGuire DK, Bertoni AG, Kitzman D, et al. Association of intensive lifestyle intervention, fitness, and body mass index with risk of heart failure in overweight or obese adults with type 2 diabetes mellitus: an analysis from the look AHEAD trial. Circulation. 2020;141(16):1295-306.

7. Trikkalinou A, Papazafiropoulou AK, Melidonis A. Type 2 diabetes and quality of life. World J Diabetes. 2017:8(4):120-9.

8. American Diabetes A. 2. Classification and diagnosis of diabetes: standards of medical care in diabetes-2020. Diabetes Care. 2020;43(Suppl 1):S14-31.

9. Ponikowski P, Voors AA, Anker SD, Bueno H, Cleland JGF, Coats AJS, Falk V, Gonzalez-Juanatey JR, Harjola VP, Jankowska EA, et al. 2016 ESC Guidelines for the diagnosis and treatment of acute and chronic heart failure: the Task Force for the diagnosis and treatment of acute and chronic heart failure of the European Society of Cardiology (ESC) Developed with the special contribution of the Heart Failure Association (HFA) of the ESC. Eur Heart J. 2016;37(27):2129-200

10. Trico D, Nesti L, Frascerra S, Baldi S, Mengozzi A, Natali A. A protein/lipid preload attenuates glucose-induced endothelial dysfunction in individuals with abnormal glucose tolerance. Nutrients. 2020; 12(7).

11. Mueller MJ. Identifying patients with diabetes mellitus who are at risk for lower-extremity complications: use of Semmes-Weinstein monofilaments. Phys Ther. 1996;76(1):68-71.

12. Dimitropoulos G, Tahrani AA, Stevens MJ. Cardiac autonomic neuropathy in patients with diabetes mellitus. World J Diabetes. 2014;5(1):17-39.

13. Guazzi M, Bandera F, Ozemek C, Systrom D, Arena R. cardiopulmonary exercise testing: what is its value? J Am Coll Cardiol. 2017;70(13):1618-36.

14. Kosmala W, Rojek A, Przewlocka-Kosmala M, Mysiak A, Karolko B, Marwick TH. Contributions of nondiastolic factors to exercise intolerance in heart failure with preserved ejection fraction. J Am Coll Cardiol. 2016;67(6):659-70.

15. Eisman AS, Shah RV, Dhakal BP, Pappagianopoulos PP, Wooster L, Bailey C, Cunningham TF, Hardin KM, Baggish AL, Ho JE, et al. Pulmonary capillary wedge pressure patterns during exercise predict exercise capacity and incident heart failure. Circ Heart Fail. 2018;11(5):e004750.

16. Topilsky Y, Rozenbaum Z, Khoury S, Pressman GS, Gura Y, Sherez J, Man A, Shimiaie J, Edwards S, Berookhim J, et al. Mechanisms of effort intolerance in patients with heart failure and borderline ejection fraction. Am J Cardiol. 2017;119(3):416-22.

17. Borlaug BA, Kane GC, Melenovsky V, Olson TP. Abnormal right ventricularpulmonary artery coupling with exercise in heart failure with preserved ejection fraction. Eur Heart J. 2016;37(43):3293-302.

18. Brubaker PH, Kitzman DW. Chronotropic incompetence: causes, consequences, and management. Circulation. 2011;123(9):1010-20.

19. Lang RM, Badano LP, Mor-Avi V, Afilalo J, Armstrong A, Ernande L, Flachskampf FA, Foster E, Goldstein SA, Kuznetsova T, et al. Recommendations for cardiac chamber quantification by echocardiography in adults: an update from the American Society of Echocardiography and the European Association of Cardiovascular Imaging. Eur Heart J Cardiovasc Imaging. 2015;16(3):233-70.

20. Pugliese NR, Fabiani I, Mandoli GE, Guarini G, Galeotti GG, Miccoli M, Lombardo A, Simioniuc A, Bigalli G, Pedrinelli R, et al. Echo-derived peak cardiac power output-to-left ventricular mass with cardiopulmonary exercise testing predicts outcome in patients with heart failure and depressed systolic function. Eur Heart J Cardiovasc Imaging. 2019:20(6):700-8

21. Pugliese NR, De Biase N, Gargani L, Mazzola M, Conte L, Fabiani I, Natali A, Dini FL, Frumento P, Rosada J, et al. Predicting the transition to and progression of heart failure with preserved ejection fraction: a weighted risk score using bio-humoural, cardiopulmonary, and echocardiographic stress testing. Eur J Prev Cardiol. 2020. https://doi.org/10.1093/eurjpc/ zwaa129.

22. Pugliese NR, Mazzola M, Fabiani I, Gargani L, De Biase N, Pedrinelli R, Natali A, Dini FL. Haemodynamic and metabolic phenotyping of hypertensive patients with and without heart failure by combining cardiopulmonary and echocardiographic stress test. Eur J Heart Fail. 2020;22(3):458-68.

23. Pugliese NR, De Biase N, Conte L, Gargani L, Mazzola M, Fabiani I, Natali A Dini FL, Frumento P, Rosada J, et al. Cardiac reserve and exercise capacity: insights from combined cardiopulmonary and exercise echocardiography stress testing. J Am Soc Echocardiogr. 2021;34(1):38-50.

24. Shimiaie J, Sherez J, Aviram G, Megidish R, Viskin S, Halkin A, Ingbir M, Nesher N, Biner S, Keren G, et al. Determinants of effort intolerance in patients with heart failure: combined echocardiography and cardiopulmonary stress protocol. JACC Heart Fail. 2015;3(10):803-14

25. Wolsk E, Kaye D, Komtebedde J, Shah SJ, Borlaug BA, Burkhoff D, Kitzman DW, Lam CSP, van Veldhuisen DJ, Ponikowski P, et al. Central and peripheral determinants of exercise capacity in heart failure patients with preserved ejection fraction. JACC Heart Fail. 2019;7(4):321-32.

26. Aspenes ST, Nilsen TI, Skaug EA, Bertheussen GF, Ellingsen O, Vatten L, Wisloff U. Peak oxygen uptake and cardiovascular risk factors in 4631 healthy women and men. Med Sci Sports Exerc. 2011;43(8):1465-73.

27. Rapp D, Scharhag J, Wagenpfeil S, Scholl J. Reference values for peak oxygen uptake: cross-sectional analysis of cycle ergometry-based cardiopulmonary exercise tests of 10090 adult German volunteers from the Prevention First Registry. BMJ Open. 2018;8(3):e018697. 
28. Corra U, Agostoni PG, Anker SD, Coats AJS, Crespo Leiro MG, de Boer RA, Harjola VP, Hill L, Lainscak M, Lund LH, et al. Role of cardiopulmonary exercise testing in clinical stratification in heart failure. A position paper from the Committee on Exercise Physiology and Training of the Heart Failure Association of the European Society of Cardiology. Eur J Heart Fail. 2018;20(1):3-15.

29. Huebschmann AG, Reis EN, Emsermann C, Dickinson LM, Reusch JE, Bauer TA, Regensteiner JG. Women with type 2 diabetes perceive harder effort during exercise than nondiabetic women. Appl Physiol Nutr Metab. 2009;34(5):851-7.

30. Kim YS, Seifert T, Brassard P, Rasmussen P, Vaag A, Nielsen HB, Secher NH, van Lieshout JJ. Impaired cerebral blood flow and oxygenation during exercise in type 2 diabetic patients. Physiol Rep. 2015;3(6):e12430.

31. Lafortuna $C L$, Proietti $M$, Agosti F, Sartorio A. The energy cost of cycling in young obese women. Eur J Appl Physiol. 2006;97(1):16-25.

32. Mancusi C, de Simone G, Best LG, Wang W, Zhang Y, Roman MJ, Lee ET, Howard BV, Devereux RB. Myocardial mechano-energetic efficiency and insulin resistance in non-diabetic members of the Strong Heart Study cohort. Cardiovasc Diabetol. 2019;18(1):56.

33. Baldi JC, Aoina JL, Oxenham HC, Bagg W, Doughty RN. Reduced exercise arteriovenous O2 difference in Type 2 diabetes. J Appl Physiol (1985). 2003;94(3):1033-8.

34. Gusso S, Hofman P, Lalande S, Cutfield W, Robinson E, Baldi JC. Impaired stroke volume and aerobic capacity in female adolescents with type 1 and type 2 diabetes mellitus. Diabetologia. 2008;51(7):1317-20.

35. Kobayashi Y, Christle JW, Contrepois K, Nishi T, Moneghetti K, Cauwenberghs N, Myers J, Kuznetsova T, Palaniappan L, Haddad F. Peripheral oxygen extraction and exercise limitation in asymptomatic patients with diabetes mellitus. Am J Cardiol. 2021. https://doi.org/10.1016/j.amjcard. 2021.03.011.

36. Vukomanovic V, Suzic-Lazic J, Celic V, Cuspidi C, Petrovic T, Grassi G, Tadic $M$. The relationship between functional capacity and left ventricular strain in patients with uncomplicated type 2 diabetes. J Hypertens. 2019;37(9):1871-6.

37. Kraigher-Krainer E, Shah AM, Gupta DK, Santos A, Claggett B, Pieske B, Zile MR, Voors AA, Lefkowitz MP, Packer M, et al. Impaired systolic function by strain imaging in heart failure with preserved ejection fraction. J Am Coll Cardiol. 2014;63(5):447-56.

38. Wang Y, Yang H, Huynh Q, Nolan M, Negishi K, Marwick TH. Diagnosis of nonischemic stage $B$ heart failure in type 2 diabetes mellitus: optimal parameters for prediction of heart failure. JACC Cardiovasc Imaging. 2018;11(10):1390-400.

39. Roberts TJ, Burns AT, Maclsaac RJ, Maclsaac Al, Prior DL, La Gerche A. Exercise capacity in diabetes mellitus is predicted by activity status and cardiac size rather than cardiac function: a case control study. Cardiovasc Diabetol. 2018;17(1):44.

40. Ha JW, Lee HC, Kang ES, Ahn CM, Kim JM, Ahn JA, Lee SW, Choi EY, Rim $\mathrm{SJ}, \mathrm{Oh} \mathrm{JK}$, et al. Abnormal left ventricular longitudinal functional reserve in patients with diabetes mellitus: implication for detecting subclinical myocardial dysfunction using exercise tissue Doppler echocardiography. Heart. 2007;93(12):1571-6.

41. Jellis CL, Jenkins C, Leano R, Martin JH, Marwick TH. Reduced end-systolic pressure-volume ratio response to exercise: a marker of subclinical myocardial disease in type 2 diabetes. Circ Cardiovasc Imaging. 2010;3(4):443-9.

42. Zahiti BF, Gorani DR, Gashi FB, Gjoka SB, Zahiti LB, Haxhiu BS, Kamberi LS. Left ventricular diastolic dysfunction in asymptomatic type 2 diabetic patients: detection and evaluation by tissue Doppler imaging. Acta Inform Med. 2013;21(2):120-3.

43. Jellis C, Wright J, Kennedy D, Sacre J, Jenkins C, Haluska B, Martin J, Fenwick J, Marwick TH. Association of imaging markers of myocardial fibrosis with metabolic and functional disturbances in early diabetic cardiomyopathy. Circ Cardiovasc Imaging. 2011;4(6):693-702.

44. Gulsin GS, Henson J, Brady EM, Sargeant JA, Wilmot EG, Athithan L, Htike ZZ, Marsh AM, Biglands JD, Kellman P, et al. Cardiovascular determinants of aerobic exercise capacity in adults with type 2 diabetes. Diabetes Care. 2020;43(9):2248-56.

45. Athithan L, Chowdhary A, Swarbrick D, Gulsin GS, Singh A, Jex N, Jain M Khan JN, Graham-Brown MPM, Wormleighton JV, et al. Male sex adversely affects the phenotypic expression of diabetic heart disease. Ther Adv Endocrinol Metab. 2020;11:2042018820927179.

46. Thaning P, Bune LT, Hellsten Y, Pilegaard H, Saltin B, Rosenmeier JB. Attenuated purinergic receptor function in patients with type 2 diabetes. Diabetes. 2010:59(1):182-9.

47. Zinman B, Wanner C, Lachin JM, Fitchett D, Bluhmki E, Hantel S, Mattheus M, Devins T, Johansen OE, Woerle HJ, et al. Empagliflozin, cardiovascular outcomes, and mortality in type 2 diabetes. N Engl J Med. 2015;373(22):2117-28.

48. Kumar N, Garg A, Bhatt DL, Sabongui S, Gupta N, Chaudhry S, Arena $\mathrm{R}$, Verma S. Empagliflozin improves cardiorespiratory fitness in type 2 diabetes: translational implications. Can J Physiol Pharmacol. 2018;96(11):1184-7.

49. Carbone S, Canada JM, Billingsley HE, Kadariya D, Dixon DL, Trankle CR, Buckley LF, Markley R, Vo C, Medina de Chazal H, et al. Effects of empagliflozin on cardiorespiratory fitness and significant interaction of loop diuretics. Diabetes Obes Metab. 2018;20(8):2014-8.

50. Chen Y, Zeng W, Chen W, Zhang Y, Zhu T, Sun J, Liang Z, Wang L, Yang Z, Wu B, et al. Evaluating the correlation of the impairment between skeletal muscle and heart using MRI in a spontaneous type 2 diabetes mellitus rhesus monkey model. Acta Diabetol. 2020;57(6):673-9.

51. Enomoto $M$, Ishizu T, Seo $Y$, Yamamoto $M$, Suzuki $H$, Shimano $H$, Kawakami Y, Aonuma K. Subendocardial systolic dysfunction in asymptomatic normotensive diabetic patients. Circ J. 2015;79(8):1749-55.

52. Koliaki C, Roden M. Alterations of mitochondrial function and insulin sensitivity in human obesity and diabetes mellitus. Annu Rev Nutr. 2016:36:337-67.

53. Schrauwen-Hinderling VB, Kooi ME, Hesselink MK, Jeneson JA, Backes WH, van Echteld CJ, van Engelshoven JM, Mensink M, Schrauwen P. Impaired in vivo mitochondrial function but similar intramyocellular lipid content in patients with type 2 diabetes mellitus and BMI-matched control subjects. Diabetologia. 2007;50(1):113-20.

54. Malin SK, Francois ME, Eichner NZM, Gilbertson NM, Heiston EM, Fabris C, Breton M. Impact of short-term exercise training intensity on beta-cell function in older obese adults with prediabetes. J Appl Physiol (1985). 2018;125(6):1979-86.

55. Eser $P$, Marcin T, Prescott E, Prins LF, Kolkman E, Bruins W, van der Velde AE, Pena-Gil C, Iliou MC, Ardissino D, et al. Clinical outcomes after cardiac rehabilitation in elderly patients with and without diabetes mellitus: the EU-CaRE multicenter cohort study. Cardiovasc Diabetol. 2020;19(1):37.

56. Montero D, Diaz-Canestro C. Determinants of exercise intolerance in heart failure with preserved ejection fraction: a systematic review and meta-analysis. Int J Cardiol. 2018;254:224-9.

57. Dhakal BP, Malhotra R, Murphy RM, Pappagianopoulos PP, Baggish AL, Weiner RB, Houstis NE, Eisman AS, Hough SS, Lewis GD. Mechanisms of exercise intolerance in heart failure with preserved ejection fraction: the role of abnormal peripheral oxygen extraction. Circ Heart Fail. 2015;8(2):286-94

58. Ross R, Blair SN, Arena R, Church TS, Despres JP, Franklin BA, Haskell WL, Kaminsky LA, Levine BD, Lavie CJ, et al. Importance of assessing cardiorespiratory fitness in clinical practice: a case for fitness as a clinical vital sign: a scientific statement from the American Heart Association. Circulation. 2016;134(24):e653-99.

59. Haykowsky MJ, Brubaker PH, John JM, Stewart KP, Morgan TM, Kitzman DW. Determinants of exercise intolerance in elderly heart failure patients with preserved ejection fraction. J Am Coll Cardiol. 2011;58(3):265-74.

\section{Publisher's Note}

Springer Nature remains neutral with regard to jurisdictional claims in published maps and institutional affiliations. 